\title{
Herbal tea bag formulation from a mixture of black tea, cinnamon, and cardamon with mixture design method
}

\author{
S.C. Batubara ${ }^{1}$, F. Nurkolis ${ }^{2}$ and S. Putri ${ }^{1}$ \\ ${ }^{1}$ Department of Food Sciences and Technology, Faculty of Food Technology and Health, Sahid University of Jakarta, \\ South Jakarta, Indonesia and \\ ${ }^{2}$ Department of Biological Sciences, Faculty of Sciences and Technology, State Islamic University of Sunan Kalijaga, \\ Yogyakarta, Indonesia
}

Tea is a drink that is liked by all ages. Apart from its fresh taste, tea also has properties for health ${ }^{(1)}$. Cinnamon and cardamom are great sources of antioxidants. Cinnamon contains cinnamaldehyde, eugenol, cinnamic acid, catechins, epicatechins, and other polyphenol compounds ${ }^{(2)}$. The bioactive components in cardamom, such as cineol, terpineol, borneol, saponins, flavonoids, and polyphenols are also known to have antioxidant activity that is beneficial to health ${ }^{(3)}$. So that the combination of black tea, cinnamon and cardamom is possible if it is made into herbal teas. The purpose of this research is to obtain an optimal formulation of the herbal teabags that made from black tea, cinnamon and cardamom.

This study used Design Expert Application with Design Mixture D-optimal method. Responses in this studies are physical test by colour intensity, chemical test by total phenol value, antioxidant activity, moisture content, ash content, and sensory response are colour, flavour, and aroma. This Study using 35 panelise. The data were processed using ANOVA which has been provided in the Design Expert $7 \AA$ program. An optimal formulation determined based on desirability number.

Herbal teabags that made from black tea, cinnamon and cardamom, of the 16 formulations that has offered to produce an optimal formulation based on desirability. The optimum herbal tea bag formulation which contains $43.62 \%$ black tea, $11.38 \%$ cinnamon and $45.00 \%$ cardamom. The formulation has been resulted by program $70.87 \%$ colour intensity, $7.18 \%$ water content, $0.07 \%$ ash content, total phenol $3.2 \mathrm{mgGAE} / \mathrm{g}$, antioxidant activity $1.07 \mu \mathrm{g} / \mathrm{mL}$ (IC50), 3.64 hedonic colour (like-very like), 3.4), and a flavour of 3.56 (like-very like), colour is 4.28 (slightly reddish brown), aroma is 4.32 (strong) and flavour is 4.16 (not bitter).

The optimum formulation is composed by tea $43.62 \%$, cinnamon $11.38 \%$, and cardamom $45.00 \%$. The characteristics of the tea produced were water content of $7.18 \%$, ash content of $0.07 \%$, total phenol $3.2 \mathrm{mgGAE} / \mathrm{g}$, antioxidant activity of $1.07 \mu \mathrm{g} / \mathrm{mL}$ (IC50) and colour intensity of $70.87 \%$.

\section{Acknowledgements}

We thank Sahid University and all of responders for their outstanding help in formatting the original communications.

\section{References}

1. Khan N \& Mukhtar H (2018) Nutrients 11(1), 39

2. Friedman M, Kozukue N \& Harden LA (2000) J Agric Food Chem 48(11), 5702-9

3. Chakraborty S, Paul K, Mallick P, et al. (2019) J Nutr Sci 24, 8:e32 